\title{
Psychosocial Boundaries Leading Towards Women Low Economic Participation
}

\author{
Munazza Madani \\ Kaneez Fatima Mamdani \\ \& \\ Huzaifa Sarfraz \\ Department of Sociology \\ University of Karachi
}

\begin{abstract}
Females are less in numbers when it comes to professional life, females are far behind in economic independence; male gender is the one which is ruling in labour market. The ratio of working women is very low as compared to men; especially in developing nations like Pakistan, this ratio is very depressed due to many social constraints. Women are surrounded by religious, cultural and traditional pressures and gate ways which they need to pass through. All hindrances make it difficult for women to get their piece of cake without any snag. To confirm these facts, middle class women aged 20 to 50 years were interviewed. Sadaf Stress Scale (SSS) was utilized to evaluate the level of emotional and mental stress in both groups. Respondents were selected using purposive sampling. Majority women in both groups expressed marriage and children's socialization as a main hurdle in their professionalism; majority believed that it was not women's responsibility to earn. Majority unmarried working females were ready to quit their jobs if their financial problems are solved in future. The proportion of women with high level stress was found in women of non-working group, who were of opinion that careers would have been good for them but would disturb their family lives. Level of stress was low in women whose religious level was high and they were against the concept of women empowerment. Rigid and orthodox interpretation of religious and society's cultural values were found one of the important factors that held back women from economic participation.
\end{abstract}

Keywords: Working Women, Economic Participation, Cultural Values, Religious Level, Level of Stress.

$$
\begin{aligned}
& \text { تخصص }
\end{aligned}
$$

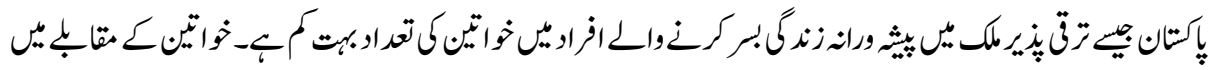

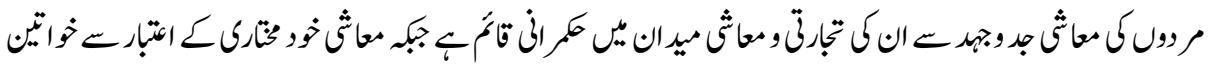

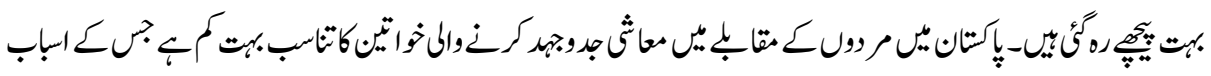

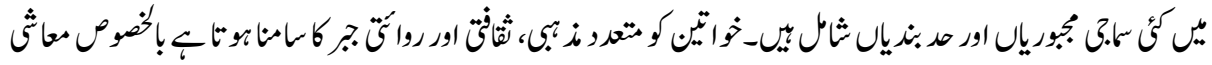

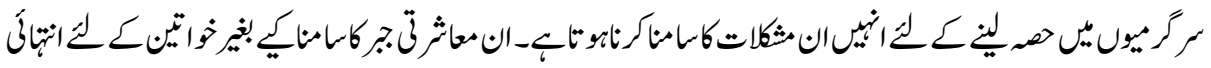




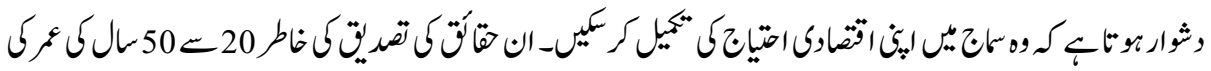

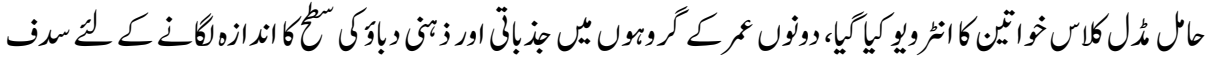

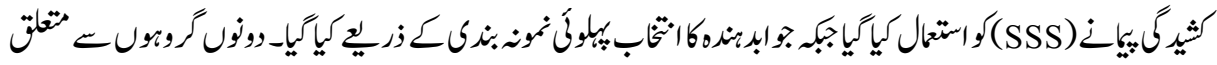

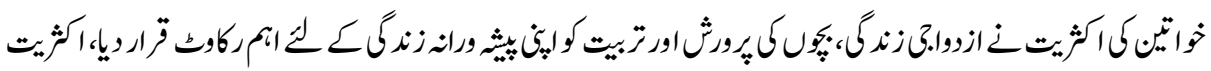

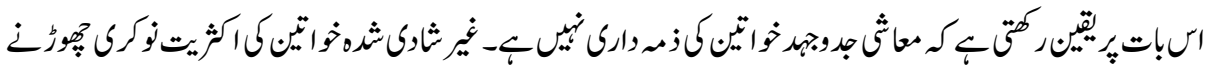

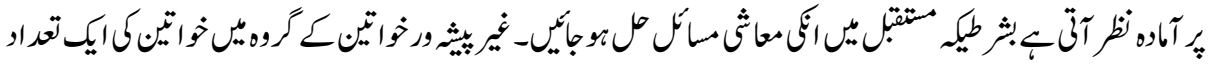

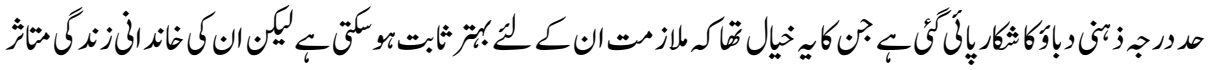

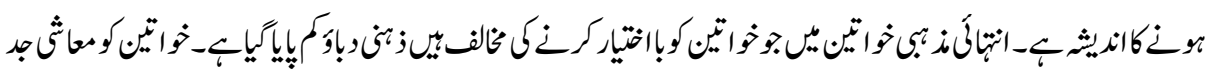

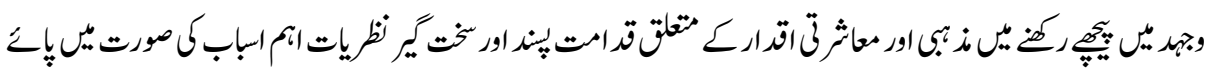

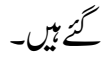

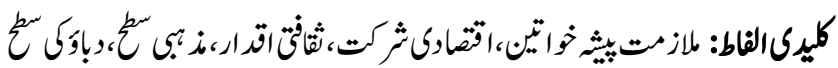

\section{Introduction}

In country like Pakistan word career is mostly confined to men. People here do not encourage women to select or pursue their career. The type of family, in Pakistan, is mostly patriarchal in nature which results in limited social roles and autonomy in other daily activities of life. Here, culture is seen as a key significance in the construction of gender identity. In Pakistani culture, woman play an important part in family and is considered pillar of a family, although, her responsibilities are limited to her on household environment where she is expected to live as a perfect house wife. She is expected to live within her home, do house chores, help serve her husband and in-laws and socialize her children according to the social standards set in Pakistani culture. On the other side working women play equal role and share the economic burden with the men of the family. Whether, a woman is working or non-working; she holds a dynamic and unchangeable status in her family. In Pakistan, women have lower literacy rates than men. According to Country Gender Profile; besides poor education; Pakistan still suffers from countless issues including low level of public spending, poverty, cultural constraints and acute regional and gender inequalities in the budgetary allocations to education. These reasons are responsible for low level of women literacy rate. According to Human Development Report-2015, globally, female participation in the labour market is $47 \%$ compared to $72 \%$ for men. 


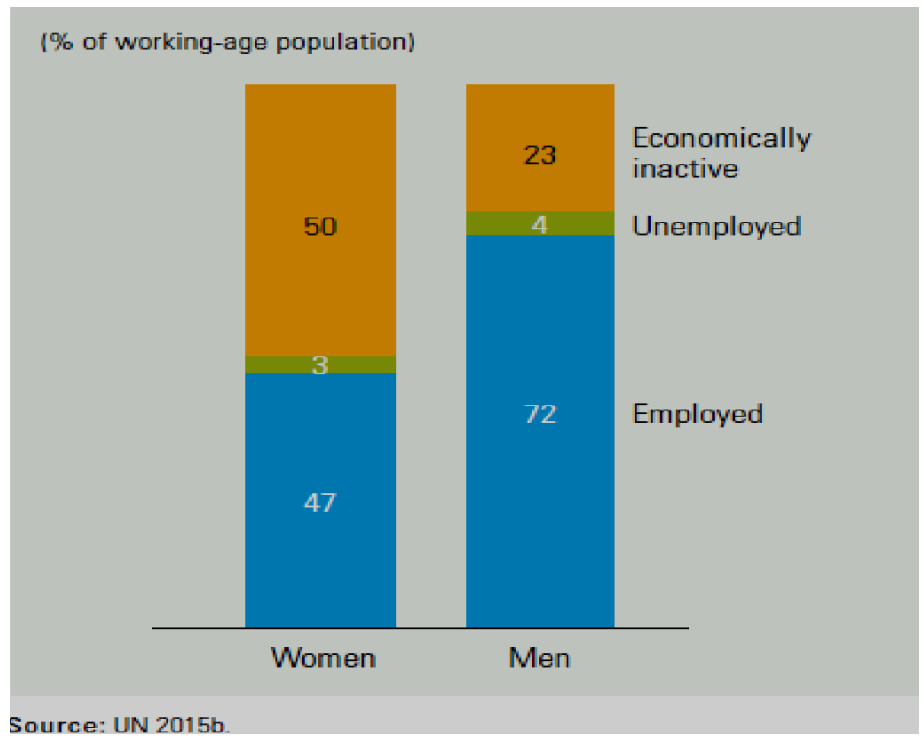

Globally, women earn 24 percent less than men. The gap is due partly to the fact that women tend to be under-represented at higher levels of pay and in higher paid occupations. But even when doing similar work, women often earn less-with the gap generally greatest for the highest paying professions.

In Pakistan, female segment of the population is comprised of about 50 percent of the total population of the country, whereas its formal participation in economic activities is minimal. Ratio of employed women is very low in Pakistan Female participation in the labour market is $10.92 \%$ compared to $34.52 \%$ for men out of total labour force participation of 45.45\% (Pakistan Economic Survey: 2014-2015). National surveys in country can provide the ratio of working genders but cannot provide the reasons behind depressed ratio of working women. Such low participation of women is, therefore, attributed to social and economic factors (Isran \& Isran, 2012).

Most of the men, irrespective of their academic and social status, prefer housewives who run their homes and rear their children. Role of women in family life is pivotal in Pakistani society, especially when woman becomes mother, all her attention and area of interest is for her child, this is because traditional roles for both men and women are predetermined (Sanchez \& Hall, 1999).Women in Pakistani society are also considered to be families' honour, and families' good reputation is highly valued and supposed to be guarded by female members of the family (Roomi \& Parrott, 2008). In a Pakistani family unit, mostly males have the role of the breadwinner and decision makers. Women are totally dependent on the male head of the family, who takes all kind of the decisions on their behalf, including the decision of doing employment; this is also a reason that women have to face a lot of barriers towards employment and when parents behave 
according to gendered rules and values in their daily lives, they influence the recognition of gender roles and provide a source for children's imitation of gender behaviour (Booth \& Amato, 1994), and those roles continue to affect young generations. Gender socialization which includes gender identification and role specific behaviour is through parents, peer, siblings, school, society and religion and social circle is said to be an important agent which affect one's attitude and thought on any issue (Auerbach, 1989). Religious knowledge and practices are also very strong motives which affect gender roles in society; there are certain defined obligations, duties and limitations in religion. Family possesses central position in religion Islam and woman is the most important component of this pivotal unit. Protection of women and her traditional role is from one of the important literature in Islam. Muslim women have the choice to either work to earn their livelihoods or they could opt for a non-working status as it is the responsibility of their husbands to earn and take care of their families. There are many verses in the Holy Quran, where men are given more responsibilities than women and in some instances make them guardians of the women in their families. As quoted in verses of Quran: "Men are in charge of women by [right of] what Allah has given one over the other and what they spend [for maintenance] from their wealth. So righteous women are devoutly obedient, guarding in [the husband's] absence what Allah would have them guard. But those [wives] from whom you fear arrogance - [first] advise them; [then if they persist], forsake them in bed; and [finally], strike them. But if they obey you [once more], seek no means against them. Indeed, Allah is ever exalted and grand" (Surat An-Nisa' [4:34]).The wives of the Last Prophet were being specifically addressed; to stay in their homes. Muslim women emulate the wives of the Prophet, considering them role models. In these circumstances, the idea of working women is not idealized in religious families. Due to the social roles of married women particularly in modern industrialized societies, role of house wife or working wife is assumed to be the source of severe mental illness by married females.

Karachi is the most populated city of Pakistan; city with a population estimated to be 24 million in 2015. Karachi is home to largest national and international corporations. The city is also a major hub of higher education in South Asia. Due to all these features, population of Karachi is very diversified and exposed to new era more than the other areas of Pakistan. Although the city of lights does not promise autonomy in women's lives because of the social, educational and religious constraints they face both directly and indirectly.

Stress arises when individuals perceive that they cannot adequately cope with the demands being made on them or with threats to their well-being (Lazarus \& Folkman, 1984). Emotional stress occurs due to long term interruption of any emotion, while mental stress is when one performs number of intellectual task (Noushad \& Ahmed, 2013). The role of house wife is still isolated in the modern society like Karachi. 
Housewives find themselves detached from the outer world which can cause prevalence of stress in non-working women, as non-working women's source of satisfaction is only within their families (Newberry, Weissman \& Myers, 1979).

\section{Literature Review}

Serious gender inequalities and human rights violation against women is present in Pakistan and women in Pakistan also face restriction and limitations of autonomy. In a study which was published in 2007, by Ali, Krantz, Gul, Asad, Johansson \& Mogren stated that in Pakistan men are the primary authority and women are their sub-ordinates; men hold superior position as compare to females adding that women routinely face gender based inequalities in and outside their homes and are confined for doing house work for their families. They highlighted unselfish, calmness, tolerance and hospitality as characteristics of good women which are directed by education, mass media and culture of society. Another persuasive argument is that many families continue to maintain the ideology that values the husband's authority, emphasizes respect for parents, and stresses differences between men and women, all of these in the face of considerable changes in actual behaviour (Lamphere, 1989). There exists some literature to give reason for women's low ratio of career persuasion after marriage in developing countries. In Pakistan women find it difficult to travel, meet their colleagues and get together at a convenient place outside their homes (Roomi\& Parrott, 2008). Bruck, Allen \& Spector, (2002) also established that married women who spend more time on work outside home are more likely experience conflict between family and work. It is noticeable that labour force participation is negatively associated with several measures of religious behaviour as Muslim women have significantly lower autonomy levels (Sabarwal, 2008), whereas Miller \& Hoffman (1995) made the argument that women are more religious than men due to the society's structure; which is low participation in labour force and more responsibility of children's upbringing and house chores. Auerbach (1989) stated in his study that there is big impact of parents' approach and attitude toward their children's career and families of different social class have relatively distinct value-orientation and that values affect behaviours. Many researchers have concentrated stress and its relationship with work force. House wives report that they feel no authority at home, they are not allowed to take any decision for themselves and on other family issues and the nature of house job is unrewarding (Radloff, 1975). Ferree (1979) also affirmed that Fulltime house wives feel themselves dissatisfied and in worse conditions as compare to the working wives, because work of housewife lack sense of competence, social connectedness and self-determination and their opinions are also not valued due to their lack in financial contribution in family, this leads to sense of powerlessness, this is why fulltime housewives report more issues of anxiety and stress than women with paid jobs; he added that paid employment of 
women can at least help them relief from problems of powerlessness, meaninglessness and social isolation.

\section{Research Methodology}

Data was collected from educated degree holder women, from which $50 \%$ were working and $50 \%$ were unemployed. Sampling was done using purposive sampling. Working women were selected from non-probability, purposive sampling. Working women were selected from Institute of Behavioural Sciences-IBS and non-working women were selected from apartments of Gulistan-e-Johar, block 10. Respondents was aged from 25 to 40. Both married and unmarried women were the part of study. All the respondents belonged from middle class economic background. Data was collected through in-depth interview. Pre-questionnaire was designed for interview with separate questionnaire of tool for evaluation of emotional and mental stress. Each respondent was interviewed separately in different timings and sittings.

Sadaf Stress Scale (SSS) was used for the evaluation of Emotional and Mental Stress in women of both groups. SSS has been developed for evaluation of stress by observing major signs \& symptoms. Classification of those symptoms were in seven different classes; physical stress, mental stress, traumatic stress, psychosocial stress, nutritional stress, emotional stress, chemical stress. The tool comprised of 114 items that differentiated physical, mental, traumatic, psychosocial, nutritional, emotional \& chemical stress. Evaluation of scale was done in four categories; normal, mild, moderate and severe. It helped the researchers with evaluation of causes of stress as it was first of its kind.

\section{Findings and Results}

Both groups showed negative response for women employment after marriage but proportion of non-working women was high. In this regard, majority of working women showed positive response on statement that working women were better life partner as shown in figure 1 above. Figure 2, illustrates the importance of environment on women career. It can be seen that majority working women had educated social circle and practice of women employment in family. 
Figure 1

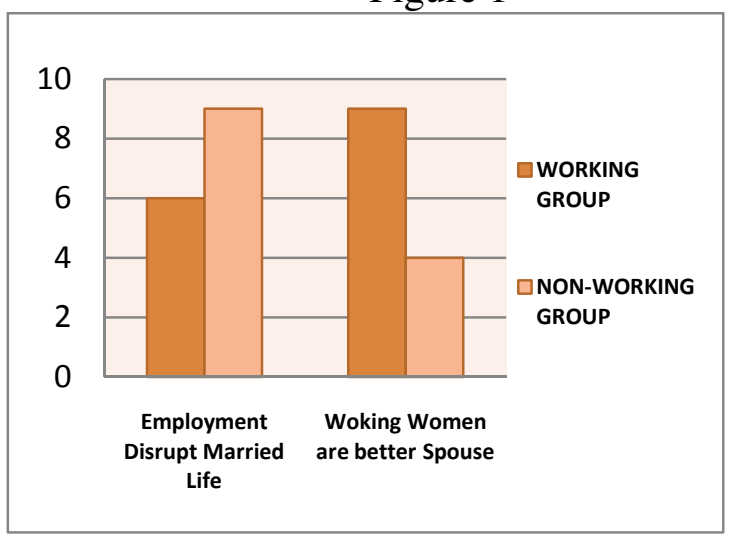

Figure 2

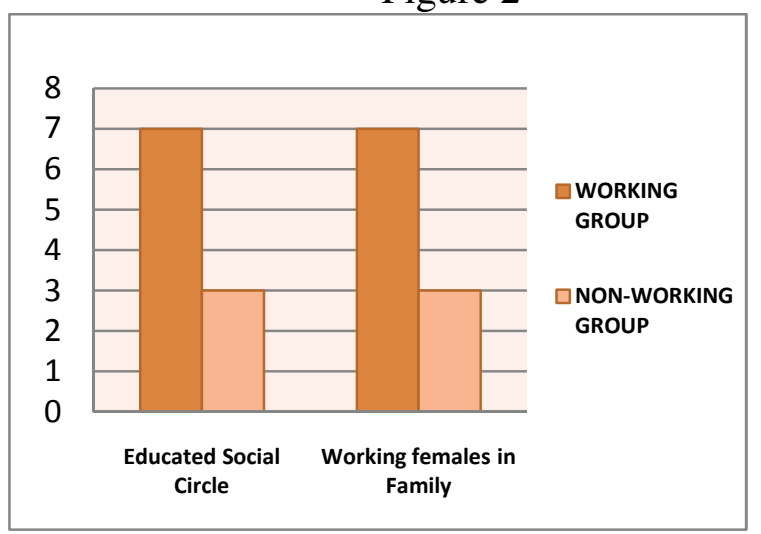

The religious level was higher in non-working group and it vice versa motivational level was higher in families of working women group as shown in figure 3. Figure 4 illustrates the level of stress found in working and non-working group of females. Females with mental stress were found more in non-working group than working group. No significant difference was found in emotional stress between these groups, but analysis of the scale showed that women in non-working group were slightly more under emotional stress than working group.

Figure 3

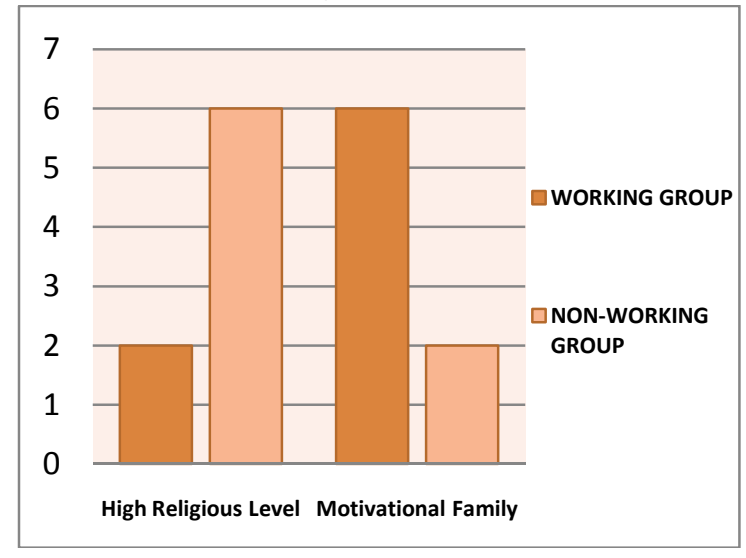

Figure 4

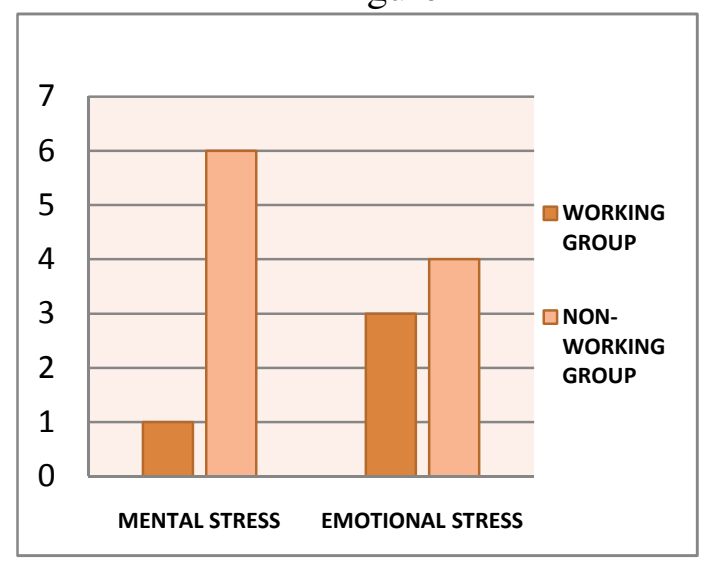

\section{Working Women Group}

$50 \%$ of women from working women showed positive response on the statement that being in career is good for a woman itself but not for her family and marital life; $60 \%$ from these women were unmarried and had no practice of working women in their families and they were ready to quit their jobs after marriage whereas, remaining $40 \%$ of 
married women belonged to families where women did not do outdoor jobs but these women were very religious and they considered concept of working women as prohibited in Islam. 50\% of working women were doing job only for financial reasons, and they were ready to quit their profession when there will be no need. The remaining 50\% argued that working women were best life partners and they had managed their family responsibilities more efficiently than non-working group. 50\% women of respondents belonged from families where women were in some kind of profession and they also had educated social circle. Out of this group, $80 \%$ were married and were doing job by their own preferences and $20 \%$ of unmarried women wanted to continue their careers after marriage.

\section{Non-Working Women Group}

In this group $80 \%$ of women considered having job to be good for women but not for their families; they argued that working mothers cannot raise and provide better socialization to their children in a competent way. Out of these $80 \%$ women; $75 \%$ had families who did not encourage the concept of working women and remaining $25 \%$ women were highly religious and were against doing any job. These $25 \%$ of women had families which motivated them for economic independence but they did not want to pursuit it as they consider it forbidden in their religion. Out of $20 \%$ of women who do not considered women economic independency good for themselves but not from their families were further divided into two categories; Out of $20 \%, 50 \%$ of them considered economic independency of women very important and they are willing to go to work but their families were not allowing them while remaining $50 \%$ of respondents belonged to orthodox families were not willing to talk about the issue of working women. They considered the idea of economic independency for women as a grand sin in religion Islam.

\section{Stress Evaluation}

In working group only $20 \%$ women were found under stress condition, $50 \%$ under mild emotional stress and 50\% under mild mental stress and mild emotional stress; $50 \%$ under mild emotional stress were those who were motivated towards their career and sometimes experienced marital issues.50\% were those who were under both mild mental and emotional stress were those who had jobs but did not want to continue due to religious values. In non-working group $60 \%$ women were found under stressful conditions. Out of $60 \%$ of respondents; $40 \%$ had mild mental stress, $15 \%$ moderate mental and $15 \%$ were under both moderate mental and emotional stress, $15 \%$ were under moderate emotional and $15 \%$ were under severe emotional stress. Women under both moderate mental and emotional stress were those who considered job necessary for women but did not want to choose it because of society's and religious values. Women under mild and moderate mental stress were those who wanted to have career, but family did not allowed them for 
joining any profession and women under moderate and severe emotional stress were those who were not satisfied with their families' decisions for them.

\section{Discussion and Conclusions}

In Pakistan men and women both are participating in professional education; though ratio of women is low in relation to men, but when it comes to the ratio of working population of country, participation of females is depressingly low. Women in Pakistan are not much involved in economic activities of their families. There are many factors behind low women economic participation which are transmitted from the culture practices of Pakistani society. Culture of Pakistani society is chiefly patriarchal, where male domination can be seen in every aspect of family life. When it comes to the bread winner of the family, men are considered to be responsible to provide for their family while women are not considered to be responsible for financial matters, although presently situation has been changed a lot; women are getting more chances to participate in almost all activities of society. A Pakistani woman has even climbed "Mount Everest"; showing that they can achieve anything if they put their minds to it. In Pakistan, large proportion of women are getting the chance to prove themselves; however not all women are allowed to compete with men in economic activities, they are just permitted for educational liberty; this scenario with women is leading towards severe psychological issues. Study findings revealed that from total respondents $65 \%$ of them realized the fact that being part of economic activities is way to high-quality life for women; but study also found that these women were not in favour of being a professional after marriage; reason behind this ideology was found in the traditional responsibilities and gender role assigned to the married women in Pakistani culture. Participants described that role of women is the most important in family especially when she is a mother and wife. Further, they emphasised that working women ignore their families for the sake of their careers and in this scenario children suffer the most as they do not get enough time and affection from their working mothers as they should. Majority of the respondents made it clear that working women cannot perform their traditional jobs (managing children and their homes) efficiently. As mentioned earlier participants made it clear that if woman works then it is impossible for her to give proper time to her family and children which are primary responsibilities of a woman. After having a hectic day at workplace and spending half of the day outside home women are either unable to or find difficulty in staying connected with their families particularly children whereas housewives can easily manage to do so. This finding was also complimented by the study that working wives tend to have greater dislike for cooking and shopping (Ali et al., 2000).For working women; after marriage responsibilities at home also increases although the same is not true for men after marriage. Respondents those showed negative response on married working women were with background with no practice of women economic independency, as also justified by Ajrouch, Blandon, \& Antonucci (2005) that individuals with same social 
economic status shared lot of similar characteristics. Overall $50 \%$ of the respondents' families had no norms of women having paid jobs and these respondents also claimed that they have never witnessed successful working women with happy marital status. They were of the opinion that majority of those women who are working were not married therefore they did not have to play dual roles which are performed at home and at workplace. According to their experiences when a working woman gets married she quits her job for the sake of happy married life and if anyone who continues her career is due to her family's financial needs. In this study social circle is found as the most significant factor which influences women's career. In working group, those respondents who already had working women in their families and social circle were highly motivated for having a career. Out of total respondents, $80 \%$ were married and had jobs without any financial needs whereas $20 \%$ were unmarried and were of opinion that they will be continuing their jobs after marriage too.

Mother-daughter association and relationship also had an immense impact on daughters' idealization of life. Since women learn from their mothers and idealize their mothers, they consistently and positively are being reinforced when they imitate their mothers' behaviours, Boyd (1989), but to some extent it was found that women did not want to have the life in same way as their mothers had, because young generation is different from previous generations and go for new approach of thinking, In addition, these mothers' adolescent daughters are the first generation that from birth are exposed to the expanded options for them; that is, the first generation of women who could aspire to being more than wives and mothers or entering traditional occupations considered or omen only such as Beautician (La Sorsa \& Fodor, 1990).

In religion Islam women's role in family is of central value, Cooke (2001); and Pakistan is officially an Islamic state, and women participation in labour force is not idealized in Islam according to the misinterpretation of Islamic values by majority of the people (Pal: 1990).People with rigid religious affiliations and affections do not cheer the environment where women can go outside their homes without any major emergency. In a Pakistani family unit, mostly males have the role of the bread earner and decision maker. In a study by Potuchek (1992) women reported that their husbands' career was more important than their own, and that their husbands were the primary providers for their families; they see breadwinning as a responsibility that ought to be for male gender and in present study majority unmarried working females reported that they will quit their profession if it will become the source of conflict in their married lives.40\% respondents of this study with high religious level openly declared that Muslim women are strictly prohibited in Islam to leave their homes without any urgent need and these participants overtly exclaimed that women are not responsible for earnings instead it is responsibility of male family members to provide comfort and fulfil all their needs. According to them, if women are working without any financial need then they are committing a great sin and those 
working women will be answerable to God on the day of judgement. In this study religion is found to be a very powerful agent where misinterpretation of the religion is manipulating their decisions. It was found that in non-working group, $20 \%$ of the women had families who encouraged them for economic independency although they consider it against Islam to pursue their careers. These women considered themselves highly religious and they were also associated with religious organizations.

In present study employed women were found under the condition of less mental and emotional stress as compared to unemployed women. Employed women also stated that wives with jobs lead more satisfactory and stable married life as compared to housewives. The reason behind this finding was that they were not dependent on any one; and they didn't want to ask for any financial help from their partners. Out of the total data; $65 \%$ of them conveyed that working women were better spouse and women with paid jobs were real partners as they and their husbands get equal tasks to do. They were also of the opinion that because of their jobs, their opinions in family matters and in decision making were considered valuable. As mentioned earlier, that wife's employment had little effect on the marital conflict and stress; husbands with working wives enjoyed happier married lives and were under less stress than men who were married to housewives, because respondents believed that working women were more responsible and task sharing wives as compared to housewives. Workingwomen group considered themselves as more understanding of the value of money and how it was earned and most importantly their husbands' appreciated them because they contributed in their husbands' financial responsibilities. Respondents those sought to have career, although circumstances in family did not allowed them to have a career and working women those family's with rigid religious values and norms did not support them; both experienced stress in their lives. The stress existed among them because these women were promised by their families that they will be allowed to pursue their careers without any hindrance, but things did not go accordingly and they were forced to get married. These women had sketched goals to fulfil but they though that their families have deceived them.

Present study has proved that there are number of factors which affect the decision of a woman that whether she is going to pursue certain profession or not. Further, decision of a woman's life is not merely her own; there are many hindrances in woman's life when decisions are to be made, whether it's her education or career. Rigidness in the interpretation, practices of religious and cultural values, traditional societal norms and practices are found to be the most important causes which are restricting women from economic independency. Family is a very vital institution which moulds the future of its members, especially female, and norms of family are greatly influenced by its social circle and practices in it. Non-working women are found more under psychological stress conditions due to confusions in their own drive and society's norms and expectations. Working females are busier but they have sense of sovereignty, further being non- 
working house wife; a woman does all the things to benefit her family and uplift its status in society although it does not affect her status and it remains the same. Now time is evolving and more women are participating in labour force for being independent and having an autonomous life. However, women, in Pakistani society where institutional practices are still rigid, are still struggling for their fair share of status in the society.

\section{Recommendations}

It is found in present study that rigid norms and practices discontinue pace of women development, therefore unnecessary restrictions should not be labelled on daughters. Social circle is also the most prominent variable affecting on women's career orientation for this reason, people should try to be part of social events where they can have companionship with educated and professional populace. Women should plan their future ahead and communicate it with their families, especially with parents, so that they can focus on their planned future. If parents and women who are against women economic participation, they should not get enrolled in professional education programs rather they should go for those disciplines which will help them to cope with the stress levels. State should work on strengthening of institutional and legal frame work for women development keeping in view, the cultural, social and economic conditions.

\section{References}

Ajrouch, K. J., Blandon, A. Y. \& Antonucci, T. C. (2005). Social Networks among Men and Women: The Effects of Age and Socioeconomic Status. The Journals of Gerontology Series B: Psychological Sciences and Social Sciences, vol.60:6, pp.311-317.

Ali, T. S., Krantz, G., Gul, R., Asad, N., Johansson, E. \& Mogren, I. (2011). Gender Roles and their Influence on Life Prospects for Women in Urban Karachi, Pakistan: A Qualitative Study. Global Health Action; vol.4, doi: 10.3402/gha.v4i0.7448.4.

Auerbach, E. R. (1989). Toward a Social-Contextual Approach to Family Literacy. Harvard Educational Review, vol.59:2, pp.165-182.

Booth, A. (1977). Wife's Employment and Husband's Stress: A Replication and Refutation. Journal of Marriage and the Family, vol.39:4, pp.645-650.

Booth, A. \& Amato, P. R. (1994).Parental Marital Quality, Parental Divorce, and Relations with Parents. Journal of Marriage and the Family, vol.56:1, pp.21-34. doi: $10.2307 / 352698$ 
Boyd, C. J. (1989). Mothers and Daughters: A Discussion of Theory and Research. Journal of Marriage and the Family, vol.51:2, pp.291-301.

Bruck, C. S., Allen, T. D. \& Spector, P. E. (2002). The Relation between Work-Family Conflict and Job Satisfaction: A Finer-Grained Analysis. Journal of Vocational Behaviour, vol.60:3, pp.336-353.

Cooke, M. (2001).Women Claim Islam. New York and London: Routledge.

Ferree, M. M. (1976). Working-Class Jobs: Housework and Paid Work as Sources of Satisfaction. Social Problems, vol.22:4, pp.431-441.

Government of Pakistan (2015). Pakistan Economic Survey: 2014-2015, Finance Division, Islamabad, Economic Advisor's Wing, Government of Pakistan.

Human Development Report (2015).Work for Human Development. United Nations Development Programme, New York, Oxford University Press.

Isran, S. \& Isran, M. A. (2012). Low Female Labour Participation in Pakistan: Causes and Consequences. Pakistan Journal of Social Sciences, vol.32:2, pp.453-468.

La Sorsa, V. A. \& Fodor, I. G. (1990). Adolescent Daughter/Midlife Mother Dyad: A New Look at Separation and Self-Definition. Psychology of Women Quarterly, vol.14:4, pp.593-606.

Lamphere, L. (1986). From Working Daughters to Working Mothers: Production and Reproduction in an Industrial Community. American Ethnologist, vol.13:1, pp.118-130.

Lazarus, R. S. \& Folkman, S. (1984). Stress. Appraisal, and Coping, p.725.

Miller, A. S. \& Hoffmann, J. P. (1995). Risk and Religion: An Explanation of Gender Differences in Religiosity. Journal for the Scientific Study of Religion, vol.34:1pp.63-75.

Newberry, P., Weissman, M. M. \& Myers, J. K. (1979).Working Wives and Housewives. American Journal of Orthopsychiatry, vol.49:2, pp.282-291.

Noushad, S. \& Ahmed, S. (2013). Novel Stress Evaluating Tool; Sadaf Stress Scale (SSS), Tested So Far On Pakistani Population. International Journal on Endorsing Health Science Research, vol.1:2. 
Pal, I. D. (1990).Women and Islam in Pakistan. Middle Eastern Studies, vol.26:4, pp.449464.

Potuchek, J. L. (1992). Employed Wives' Orientations to Breadwinning: A Gender Theory Analysis. Journal of Marriage and the Family, vol.54:3, pp.548-558.

Radloff, L. (1975). Sex Differences in Depression. Sex Roles, vol.1:3, pp.249-265.

Roomi, M. A. \& Parrott, G. (2008).Barriers to Development and Progression of Women Entrepreneurs in Pakistan. Journal of Entrepreneurship, vol.17:1, pp.59-72.

Sabarwal, S. (2008). Impact of Mother's Education on the Relative Survival Probability of Girls in the Household (Doctoral dissertation, University Of Minnesota).

Sánchez, L. \& Hall, C. S. (1999). Traditional Values and Democratic Impulses: The Gender Division of Labour in Contemporary Spain. Journal of Comparative Family Studies, vol.30:4, pp.659-685.

Dr. Munazza Madani is an Assistant Professor in the Department of Sociology, University of Karachi.

Dr. Kaneez Fatima Mamdani is an Assistant Professor in the Department of Sociology, University of Karachi.

Ms. Huzaifa Sarfaraz is M.Phil student in the Department of Sociology, University of Karachi. 